\title{
A STUDY OF PREVALENCE OF MUSCULOSKELETAL DISORDER AMONG THE RICE MILL WORKERS IN KARIMNAGAR
}

\author{
Mohan A. Darbastwar', Bharat Kumar' ${ }^{2}$ A. Ravinder ${ }^{3}$
}

${ }_{1}^{1}$ Associate Professor, Department of Community Medicine, Chalmeda Anand Rao Institute of Medical Sciences, Karimnagar. 2Post Graduate Student, Department of Community Medicine, Chalmeda Anand Rao Institute of Medical Sciences, Karimnagar. ${ }^{3}$ Statistician, Department of Community Medicine, Chalmeda Anand Rao Institute of Medical Sciences, Karimnagar.

\section{ABSTRACT}

\section{BACKGROUND}

Rice mill industry is the oldest and largest agro based industry. Load handling, i.e. lifting and carrying heavy load of grain filled sacs is the major job component. One of the most common work-related injuries is the development of musculoskeletal disorders caused by heavy lifting and performing the task that required repetitive motions. This made us to study the prevalence of musculoskeletal disorder among the rice mill workers.

\section{AIMS AND OBJECTIVES}

To study socio-demographic profile of rice mill workers. To study the prevalence of musculoskeletal disorder among the rice mill workers. To study the association of duration of work in rice mill and musculoskeletal disorders in rice mill workers.

\section{MATERIAL AND METHODS}

Study Design: Cross-sectional study. Study Setting: Rice mills of Karimnagar Mandal. Study Period: 12 months. Study Population: All the permanent workers working were included.

\section{RESULTS AND DISCUSSION}

Among the total study subjects $34 \%$ were illiterate, $66 \%$ were belonging to class IV and V socio-economic status. Majority (50.7\%) of the male workers have an occupational history more than 10 years. Similarly, majority (38.9\%) of the female workers have an occupation history of $<5$ years. Among them predominantly pain in the Low Back is common in $27.1 \%$ followed by Knee pain in 25\%, Ankle/Feet pain in 20.5\%, Hips/Thigh pain in 17.6\%, Upper Back pain in 15\%, Shoulder pain in $25.6 \%$, Elbow in $22.4 \%$, Neck pain in $20.8 \%$ and pain in wrist/hands in $11.7 \%$. In the study subjects, $45.7 \%(125 / 273)$ workers having musculoskeletal manifestations and more than half of them (57.6\%) are working in rice mills $>10$ yrs. followed by $25.6 \%$ in $5-10$ yrs. and $16.8 \%$ in $<5$ yrs.

\section{CONCLUSION}

Musculoskeletal complaints (45.7\%) in rice mill workers were significantly associated with duration of work (Years).

\section{KEYWORDS}

Prevalence, Musculoskeletal Disorder, Rice Mill Workers.

HOW TO CITE THIS ARTICLE: Darbastwar MA, Kumar B, Ravinder A. A study of prevalence of musculoskeletal disorder among the rice mill workers in Karimnagar. J. Evolution Med. Dent. Sci. 2016;5(21):1106-1110, DOI: 10.14260/jemds/2016/257

\section{INTRODUCTION}

Asia accounts for $90 \%$ of the production and consumption of rice. Only about 35 million tons of rice is traded through international market. Leading rice exporting countries are Thailand, Vietnam, USA, India and Pakistan. Thus, it is imperative that rice production and supply for domestic consumption is entirely the national responsibility.(1)

India has the world's largest area under rice with 44.0 million ha and is the second largest producer (96.0 million tonnes - 2010) next only to China. It contributes 21.5 percent of global rice production. During 2007-08, India exported a record of 6.5 million tons of rice worth Rs. 12000 crores and was second to Thailand. Rice export contributes nearly $25 \%$ of total agriculture export from the country. However, productivity of rice is only 2.1 tons/ha (Milled rice) which is lower than world's average productivity of 2.9 tons/ha (FAO, 2009).(2)

Financial or Other, Competing Interest: None.

Submission 08-02-2016, Peer Review 27-02-2016,

Acceptance 03-03-2016, Published 14-03-2016.

Corresponding Author:

Dr. Mohan A. Darbastwar,

502, B Block, CAIMS Campus,

Karimnagar-505001, Telangana State.

E-mail:drdmonty@gmail.com

DOI: $10.14260 /$ jemds $/ 2016 / 257$
Around $58.45 \%$ of the Indian population mainly depends on agriculture for their livelihood.(3) Andhra Pradesh is the fifth largest state in India accounting for 9 and 8 percent of the country's area and population respectively. Andhra Pradesh is one of the major paddy cultivated state in India.

Karimnagar is the fifth largest district in Andhra Pradesh based on rice production and cultivation. It occupies $16 \%$ of rice area of the state. Karimnagar district has 1 , 87,576 hectares of area for cultivation of rice. It produces 6 , 02,047 tons of rice and $3210 \mathrm{~kg} / \mathrm{ha}$ is the yield. There are totally $1,24,347$ rice mills in India.(4)

Rice mill workers are potentially exposed to organic and inorganic dusts and synthetic chemicals that may have adverse effects on respiratory health. Several reports have suggested that unprotected dust exposures in agricultural settings may lead to pulmonary fibrosis. There have been many reports on health effects of grain dust exposure. Grain dust has a long history of association with disease and its adverse effects on various organs such as eyes, nose, skin, lung and the airways have been described. Asthma has been well documented as being a result of exposure. However, a few studies have been reported on the effect of rice-husk dust exposure. Rice husk is known to have high silica content. 
This biogenic silica may cause pulmonary disease resembling asbestosis, namely pleural thickening, fibrosis and possibly bronchogenic carcinoma.(5)

Load handling, i.e. lifting and carrying heavy load of grain filled sacs is the major job component. Often, the workers have to adopt awkward postures to carry out the job. Working with heavy load in awkward posture leads to physiological strain and musculoskeletal problem. Only a few report of ergonomic study on grain handling workers is available.(6)

One of the most common work-related injuries to occur globally is the development of musculoskeletal disorders caused by heavy lifting and performing tasks that require repetitive motions.(7)

Labour shortage is another major limitation in view of migration of poor from Rural to Urban. There is depletion of their health status with direct or indirect exposure to the dust at different places of work in the workplace (Rice mill). This morbidity pattern may disturb their regular work, which may affect the gross production of most needed commodity (Rice) of the state. This made me to focus on the morbidity pattern and the working condition among the workers in rice mill industry.

\section{AIMS}

To "Study of Prevalence of Musculoskeletal Disorder among the Rice Mill Workers in Karimnagar."

\section{OBJECTIVES}

1. To study socio-demographic profile of rice mill workers.

2. To study the prevalence of musculoskeletal disorder among the rice mill workers.

3. To study the association of duration of work in rice mill and musculoskeletal disorders in rice mill workers.

\section{MATERIALS AND METHODS}

\section{Study Setting}

There are 29 Rice mills in Karimnagar Mandal scattering within $35 \mathrm{~km}$ stretch from Karimnagar Town.

\section{Study Design}

It is a cross-sectional study.

\section{Study Period}

From October 2011 to October 2012.

\section{Study Population \\ Type of Sampling}

\section{Rice Mills}

The present study was conducted in 20 Rice mills out of 29 Rice mills. These were selected by taking into consideration the administration and operational issue during the study period from Oct 2011-Oct 2012.

\section{Workers}

All the supervisors, clerks, operators, weighers, coolies and helpers working permanently in the 20 Rice mills of Karimnagar Mandal are included in the study. Total 284 permanent workers were available in 20 Rice mills. Out of 284,11 subjects were not available after repeated attempts to interview them. Finally, 273 subjects included for the study.

\section{Inclusion Criteria}

Only permanent workers were included.

\section{Exclusion Criteria}

Those who were not ready to give consent were excluded from the study.

\section{Study Tools}

A semi-structured pre-tested questionnaire was used to collect relevant information through interviewing study subjects. The questionnaire was divided into four parts.

- Socio-demographic profile.

- Brief occupational history.

- Physical examination (Anthropometric measurements and vitals).

\section{Study Procedure}

There are 29 Rice mills in Karimnagar Mandal during the study period (Oct 2011-Oct 2012). Institutional Ethical Committee permission was taken. Before starting the study, a prior permission was taken from Karimnagar district Rice millers' welfare association to conduct the study in all the 29 Rice mills available in Karimnagar Mandal. Even though after taking permission when approached individually, 9 out of 29 rice mills did not give consent to conduct study with their workers due to various reasons. In 9 rice mills which were excluded from the study, the working hours, working hierarchy, socioeconomic conditions of the workers seemed to be similar to the remaining 20 rice mills, so the study was conducted in remaining 20 rice mills. Each rice mill enrolled 12-18 permanent workers (Supervisors, clerks, operators, weighing workers, coolies and helpers).

The regular attendance of contract employees to the rice mill is inconsistent and highly irregular, so only the permanent workers employed in $r$ ice mills were considered as study subjects. Totally, 284 permanent workers were available in the 20 rice mills. Of the 284 study subjects available, 11 subjects were not available after repeated attempts to interview them. Three attempts were made to cover missing subjects and each rice mill was visited 2-4 times to cover all the study subjects. Finally, a total of 273 study subjects were concluded to take part in the study. All the subjects who are supposed to be studied in the setting are included in the study.

Each rice mill was informed one day prior about our visit through the phone call as their numbers were taken from the association. Prior to the data collection, the purpose of the study was clearly explained to the study subjects and consent was taken from everyone. A good rapport was developed with study subjects and strict confidentiality was assured before starting the interview process.

\section{Data Analysis}

Data was entered into Microsoft Excel version 2007. The data then transferred to SPSS version 20 and analysed by using the following statistical test wherever necessary and the $\mathrm{P}$ value $<0.05$ was considered significant among the difference observed in the groups.

\section{Ethical Review}

The Institutional Ethical Committee of Chalmeda Anand Rao Institute of Medical Sciences, Karimnagar, after examining the study proposal has approved it. Before the study was actually started, written permission was taken from Rice Millers' Welfare Association of Karimnagar district. 
Informed consent of all study subjects were taken to confirm willingness to participate in the study.

\section{RESULTS AND DISCUSSION}

In this study among Rice Mill workers in Karimnagar Mandal, majority of the study subjects $(67 \%)$ are falling in the age group of 28 yrs. -47 yrs. and $74 \%$ of these are males. (Table No. 1) The Predominant religion followed among study subjects is Hinduism (71\%) followed by 18\% are Muslims, $8 \%$ Christians and 3\% Buddhist (Table No. 2).

In this study, $65.6 \%$ of the rice mill workers are rural residents and rest are urban residents; $67.7 \%$ of the males are rural residents, whereas female rural residents are $59.7 \%$. (Table No. 3) The distribution of rice mill workers according to education status shows $34 \%$ of the study subjects are illiterates (Table No. 4).

In this study, the study subjects are grouped based on Modified BG Prasad's Socio-Economic Scale. According to this, $66 \%$ of the subjects belong to low socioeconomic status (Class IV and V). (Table No. 5) The type of work is categorized among the study subjects in rice mills are helpers $(19 \%)$, Coolies (47\%), Weighers (7.7\%), Operators (16\%), Clerks and Supervisors (12.4\%) (Table No. 6).

In this study, majority of the workers have worked in the rice mills (Occupational History) for more than 10 yrs. (45\%), 5-10 yrs. (29\%) and $<5$ yrs. are 26\%. Majority $(50.7 \%)$ of the male workers have an occupational history more than 10 years. Similarly, majority (38.9\%) of the female workers have an occupation history of $<5$ years (Table No. 7).

In the study subjects $70 \%$ are the Coolies, $33.3 \%$ are weighers, $31 \%$ of Helpers, $25 \%$ of Operators, $17.6 \%$ of Supervisors and $11.7 \%$ of Clerks are having musculoskeletal disorders at the time of interview (Table No. 8).

In this study, 125 subjects have musculoskeletal disorders since last 12 months. Among them predominantly pain in the low back ache is common in $27.1 \%$ followed by Knee Pain in 25\%, Ankle/Feet pain in 20.5\%, Hips/Thigh pain in $17.6 \%$, Upper Back pain in $15 \%$, Shoulder pain in $25.6 \%$, Elbow in $22.4 \%$, Neck pain in $20.8 \%$ and pain in Wrist/Hands in $11.7 \%$ in decreasing order of frequency (Table No. 9).

In the study, subjects having musculoskeletal manifestations are $45.7 \%$ (125/273) among the workers having musculoskeletal manifestations, more than half of them $(57.6 \%)$ are working in rice mills $>10 \mathrm{yrs}$. followed by $25.6 \%$ in $5-10$ yrs. and $16.8 \%$ in $<5$ yrs. With increased duration of work in rice mill from $<5$ yrs. to $>10$ yrs., the musculoskeletal manifestations are increasing in the study subjects and the results are statistically significant $(\mathrm{P}=0.0002669)$ (Table No. 10).

Musculoskeletal complaints $(45.7 \%)$ in rice mill workers were significantly associated with duration of work (Years).

The most common musculoskeletal complaints being low back pain 74 (27.1\%) and knees pain 68 (25\%). Overall, prevalence of musculoskeletal complaints among rice mill workers is $45.7 \%$ in Karimnagar Mandal.

Similar results were observed in recent study conducted in South India by Prakash S, et al. 2010. That study revealed that prevalence of respiratory morbidity [32 (42.66\%)] was significantly higher among the workers and the prevalence of chronic bronchitis could be attributed to occupational exposure to dust and smoking habits among the rice mill workers and also the duration (Years) of working.
Other important morbidities included low backache and knee joint pain, which was found in around 20 (26.66\%) workers followed by musculoskeletal pain in 15 (20\%), conjunctivitis and allergic skin diseases. He further even observed both non-specific irritant and allergic responses seem to be involved, manifesting acutely as irritation of the eyes, skin and upper respiratory tract in some cases as well as allergic nasal catarrh, respiratory difficulty and eosinophilia in others. Chronic irritant effects are seen predominantly in the eyes, whereas cases of occupational asthma are probably found in hypersensitive individuals. ${ }^{(8)}$

A study done by Pradhan et al. 2007 in West Godavari district in Andhra Pradesh, found similar findings of 59\% suffering from knee joint pain and $61.5 \%$ from low back and knee joint pain.(9)

The high percentage of musculoskeletal complaints significantly associated with rice mill workers may be due to carrying heavy loads of rice bags more than their weight and due to repetitive bending at the knee to load the sacs and carriage of heavy load in awkward postures adopted by the workers.

Since application of force is required for handling loads (Lifting, lowering, holding, carrying loads, pushing and pulling weights, etc.). The force requirements vary with the posture adopted during work.(10)

Awkward body posture also causes the work to become strenuous and the physiological costs are higher in non-erect postures than in erect postures. (11)

The occupational work of handling loads requires high muscular effort in awkward postures giving rise to musculoskeletal strains and low back signs and symptoms.(12) Turning, twisting and bending are also associated with increased incidence of low back disorders like pain, ache and discomfort.(13)

It was found that most of the activities of these workers are in the category of moderate to very heavy. The findings of the present study corroborates with the reported values of Samanta and Chatterjee.(14)

However, workloads of the jobs like spreading paddy on the unshaded floor with a wooden spreader for drying and lifting and taking off of rice sac (50 kgs.) from weighing machine were moderate or heavy.(15)(16)

But all the workers in Karimnagar Mandal are lifting paddy bags from 50-70 kgs., rice bags of 25 kgs., 50 kgs., 100 kgs. and rice husk bags of $25 \mathrm{kgs}$. in 30-45 min in this region, which are all considered to be heavy work categorization.

Bhat, et al. 1991 study showed that there was comparative decrease in PEFR/min within 1 year after the workers joined the job.(17)

\begin{tabular}{|c|c|c|c|c|c|c|}
\hline \multirow{2}{*}{$\begin{array}{c}\text { Age } \\
\text { Group }\end{array}$} & Males & \multicolumn{2}{c|}{ Females } & \multicolumn{2}{c|}{ Total } \\
\cline { 2 - 7 } & No. & $\mathbf{\%}$ & No. & $\mathbf{\%}$ & No. & $\%$ \\
\hline $18-27$ & 40 & 19.9 & 10 & 13.89 & 50 & 18.31 \\
\hline $28-37$ & 62 & 30.8 & 23 & 31.95 & 85 & 31.13 \\
\hline $38-47$ & 68 & 33.8 & 31 & 43.05 & 99 & 36.26 \\
\hline$>=48$ & 31 & 15.4 & 8 & 11.11 & 39 & 14.3 \\
\hline Total & $\mathbf{2 0 1}$ & $\mathbf{1 0 0}$ & $\mathbf{7 2}$ & $\mathbf{1 0 0}$ & $\mathbf{2 7 3}$ & $\mathbf{1 0 0}$ \\
\hline Table 1: Table showing distribution of study subjects \\
according to Age and Gender \\
\hline
\end{tabular}




\begin{tabular}{|c|c|c|c|c|c|c|}
\hline \multirow{2}{*}{ Religion } & Males & \multicolumn{3}{|c|}{ Females } & \multicolumn{2}{|c|}{ Total } \\
\cline { 2 - 7 } & No. & \% & No. & \% & No. & \% \\
\hline Hindu & 143 & 71.1 & 51 & 70.84 & 194 & 71.06 \\
\hline Muslim & 36 & 17.9 & 13 & 18.06 & 49 & 17.95 \\
\hline Christian & 16 & 7.96 & 6 & 8.33 & 22 & 8.05 \\
\hline Buddhist & 6 & 2.98 & 2 & 2.77 & 8 & 2.94 \\
\hline Total & $\mathbf{2 0 1}$ & $\mathbf{1 0 0}$ & $\mathbf{7 2}$ & $\mathbf{1 0 0}$ & $\mathbf{2 7 3}$ & $\mathbf{1 0 0}$ \\
\hline \multicolumn{6}{|c|}{ Table 2: Table showing distribution of } \\
study subjects according to Religion \\
\hline
\end{tabular}

\begin{tabular}{|c|c|c|c|c|c|c|}
\hline & \multicolumn{2}{|c|}{ Male } & \multicolumn{2}{c|}{ Female } & \multicolumn{2}{c|}{ Total } \\
\hline Residence & No. & $\mathbf{\%}$ & No. & $\mathbf{\%}$ & No. & \% \\
\hline Urban & 65 & 32.3 & 29 & 40.3 & 94 & 34.4 \\
\hline Rural & 136 & 67.7 & 43 & 59.7 & 179 & 65.6 \\
\hline Total & $\mathbf{2 0 1}$ & $\mathbf{1 0 0}$ & $\mathbf{7 2}$ & $\mathbf{1 0 0}$ & $\mathbf{2 7 3}$ & $\mathbf{1 0 0}$ \\
\hline
\end{tabular}

Table 3: Table showing distribution of study subjects according to Residence

\begin{tabular}{|c|c|c|}
\hline Qualification & No. & $\%$ \\
\hline Post Graduate & 2 & 0.74 \\
\hline Graduate & 12 & 4.39 \\
\hline Diploma & 44 & 16.12 \\
\hline Secondary Level & 54 & 19.78 \\
\hline Middle School & 27 & 9.89 \\
\hline Primary & 42 & 15.38 \\
\hline Illiterate & 92 & 33.7 \\
\hline Total & 273 & 100 \\
\hline \multicolumn{3}{|c|}{$\begin{array}{l}\text { Table 4: Table showing distribution of study } \\
\text { subjects according to Education status }\end{array}$} \\
\hline
\end{tabular}

\begin{tabular}{|c|c|c|}
\hline Socio-Economic Class & No. & $\mathbf{\%}$ \\
\hline Class I & 17 & 6.22 \\
\hline Class II & 47 & 17.21 \\
\hline Class III & 30 & 10.98 \\
\hline Class IV & 127 & 46.53 \\
\hline Class V & 52 & 19.06 \\
\hline Total & $\mathbf{2 7 3}$ & $\mathbf{1 0 0}$ \\
\hline
\end{tabular}

Table 5: Table showing distribution of study subjects according to B.G. Prasad Classification

\begin{tabular}{|c|c|c|}
\hline Type of Work & No. & $\%$ \\
\hline Supervisors & 17 & 6.22 \\
\hline Clerks & 17 & .22 \\
\hline Operators & 44 & 16.13 \\
\hline Weighers & 21 & 7.69 \\
\hline Coolies & 122 & 44.68 \\
\hline Helpers & 52 & 19.06 \\
\hline Total & 273 & 100 \\
\hline \multicolumn{3}{|c|}{$\begin{array}{c}\text { Table 6: Table showing distribution of study } \\
\text { subjects according to Type of Work }\end{array}$} \\
\hline
\end{tabular}

\begin{tabular}{|c|c|c|c|c|c|c|}
\hline & \multicolumn{2}{|c|}{ Male } & \multicolumn{2}{c|}{ Female } & \multicolumn{2}{c|}{ Total } \\
\hline Duration of Work & No. & $\mathbf{\%}$ & No. & $\mathbf{\%}$ & No. & $\mathbf{\%}$ \\
\hline$<5$ yrs. & 43 & 21.4 & 28 & 38.9 & 71 & 26.0 \\
\hline 5-10 yrs. & 56 & 27.9 & 23 & 31.9 & 79 & 28.9 \\
\hline$>10$ yrs. & 102 & 50.7 & 21 & 29.2 & 123 & 45.1 \\
\hline Total & $\mathbf{2 0 1}$ & $\mathbf{1 0 0}$ & $\mathbf{7 2}$ & $\mathbf{1 0 0}$ & $\mathbf{2 7 3}$ & $\mathbf{1 0 0}$ \\
\hline
\end{tabular}

Table 7: Table showing distribution of study subjects according to Duration of work in years

\begin{tabular}{|c|c|c|c|c|c|c|}
\hline \multirow{2}{*}{ Type of Work } & \multicolumn{7}{|c|}{ Musculoskeletal Disorders } \\
\cline { 2 - 7 } & Yes & $\mathbf{\%}$ & No & $\mathbf{\%}$ & Total & $\mathbf{\%}$ \\
\hline Supervisors & 3 & 2.4 & 14 & 9.5 & 17 & 6.2 \\
\hline Clerks & 2 & 1.6 & 15 & 10.1 & 17 & 6.2 \\
\hline Operators & 11 & 8.8 & 33 & 22.3 & 44 & 16.1 \\
\hline Weighers & 7 & 5.6 & 14 & 9.5 & 21 & 7.7 \\
\hline Coolies & 86 & 68.8 & 36 & 24.3 & 122 & 44.7 \\
\hline Helpers & 16 & 12.8 & 36 & 24.3 & 52 & 19.0 \\
\hline Total & $\mathbf{1 2 5}$ & $\mathbf{1 0 0}$ & $\mathbf{1 4 8}$ & $\mathbf{1 0 0}$ & $\mathbf{2 7 3}$ & $\mathbf{1 0 0}$ \\
\hline
\end{tabular}

Table 8: Table showing distribution of Study Subjects according to Type of Work and Musculoskeletal Disorders

\begin{tabular}{|c|c|c|c|c|c|c|}
\hline \multicolumn{7}{|c|}{ Musculoskeletal Manifestations } \\
\hline Site & Yes & \% & No & \% & Total & \% \\
\hline Neck pain & 26 & 9.5 & 247 & 90.5 & 273 & 100 \\
\hline Shoulder pain & 32 & 11.7 & 242 & 88.3 & 273 & 100 \\
\hline Elbow pain & 28 & 10.2 & 245 & 89.8 & 273 & 100 \\
\hline Wrists/Hands pain & 23 & 8.4 & 250 & 91.6 & 273 & 100 \\
\hline Upper back pain & 41 & 15 & 232 & 85 & 273 & 100 \\
\hline Low back pain & 74 & 27.1 & 199 & 72.9 & 273 & 100 \\
\hline Hips/Thighs pain & 48 & 17.6 & 225 & 82.4 & 273 & 100 \\
\hline Knees pain & 68 & 25 & 205 & 75 & 273 & 100 \\
\hline Ankles/Feet pain & 56 & 20.5 & 217 & 79.5 & 273 & 100 \\
\hline $\begin{array}{c}\text { Table 9: Table showing distribution of subjects having } \\
\text { Musculoskeletal Manifestations since last 12 months }\end{array}$ \\
\hline
\end{tabular}

\begin{tabular}{|c|c|c|c|c|c|c|}
\hline \multirow{2}{*}{ Duration of Work } & \multicolumn{5}{|c|}{ Musculoskeletal Manifestations } \\
\cline { 2 - 7 } & Yes & \% & No & \% & Total & \% \\
\hline$<5$ yrs. & 21 & 16.8 & 50 & 33.8 & 71 & 26.0 \\
\hline $5-10$ yrs. & 32 & 25.6 & 47 & 31.8 & 79 & 28.9 \\
\hline$>10$ yrs. & 72 & 57.6 & 51 & 34.5 & 123 & 45.1 \\
\hline Total & $\mathbf{1 2 5}$ & $\mathbf{1 0 0}$ & $\mathbf{1 4 8}$ & $\mathbf{1 0 0}$ & $\mathbf{2 7 3}$ & $\mathbf{1 0 0}$ \\
\hline
\end{tabular}

Table 10: Table showing association of Musculoskeletal manifestations with Duration of Work

Chi Square $=16.46, \mathrm{df}=2, \mathrm{p}$-value $=0.0002669$

\section{CONCLUSION}

The study was conducted on 273 rice mill workers in 20 rice mills; it was found that 201 workers were males $(73.3 \%)$ and $72(26.7 \%)$ were females, majority of study subjects 183 $(67 \%)$ were in the age group of 28 to 47 years. Religion wise 194 (71\%) are Hindus. Total 179 (66\%) rice mill workers live in the rural area and 94 (34\%) were living in urban area; 179 $(66 \%)$ study subjects were falling under low socio-economic status (Class IV and V); 92 (34\%) study subjects are Illiterates. 
124 (45\%) study subjects have habit of drinking alcohol; 89 (33\%) workers are smokers, 77 (28.2\%) were current smokers; 12 (4.4\%) were former smokers. Among 77 current smokers, 73 (36\%) are males and 4 (5.5\%) are females; 123 (45\%) rice mill workers are having an occupational history of more than 10 years; 102 (51\%) Male workers have 10 and >10 years work experience; 28 (39\%) Female workers have work experience less than 5 years.

$103(38 \%)$ of rice mill workers are symptom free and rest have symptoms. Body mass index of $56(78 \%)$ females is $<23 \mathrm{~kg} / \mathrm{m} 2,111$ (55\%) males are $<23 \mathrm{~kg} / \mathrm{m} 2$. Newly diagnosed hypertensives are Grade I-19 (7.4\%), Grade II-4 $(1.6 \%)$ and pre-hypertensives are 21 (8.2\%). Association of hypertension with years of working is significant with $\mathrm{P}=0.0028$.

The prevalence of low back ache is $27 \%$ ( 74 workers) and knee pain 25\% (68 workers). Association of musculoskeletal complaints with duration of work was found, observations are significant $\left(\mathrm{P}=0.0002669^{*}\right)$.

\section{Limitations}

- The study results reflect only $20(69 \%)$ rice mills in Karimnagar Mandal.

- Poor maintenance of records in the rice mills is the reason why we could not study Sickness Absenteeism.

\section{ACKNOWLEDGEMENT}

I express my whole hearted gratitude to all the rice mill workers for their sincere participation and co-operation in the success of this study. inputs.

I am also thankful to all my colleagues for their valuable

\section{REFERENCES}

1. Viraktamath BC, Bentur JS, Rao KV, et al. Vision 2030. Directorate of rice research. 2011.

http://www.drricar.org/DRR\%20vision\%202030.pdf.

2. Food and agriculture organisation. FAOSTAT. http://www.fao.org/corp/satistics. 2010.

3. Gairola BK, Neeta Varma, Alka Mishra, et al. National portal content management team. Government of India 2007.

http://www.nic.in/sites/upload_files/nichome/files/doc uments/content.pdf
4. Nayak Purusottam. Problems and prospects of rice mill modernization: a case study. Journal of Assam University 1996;1:22-28.

5. Razlan Musa, Lin Naing, Zulkifli Ahmad, et al. Respiratory health of rice millers in Kelantan, Malaysia. South-East Asian Journal of Tropical Medicine \& Public Health 2000;31:575-578.

6. Pradhan $\mathrm{CK}$, Thakur S. Work stress assessment of workers engaged in a food grain depot. Vidyasagar University, Medinipur, West Bengal. Journal of Biological Science 2002;8:23-33.

7. Kumuda Bandhu, Jadab. Occupational health hazards and safety management for industrial workers. Cuttack: Odhisa Review 2012;64-69.

8. Seema Prakash, Shashikala Manjunatha, Shashikala C. Morbidity patterns among rice mill workers: a crosssectional study. Tumkur, Bangalore: Indian Journal of Occupation \& Environmental Medicine 2010;14:91-93.

9. Chandan K Pradhan, Sridhar Thakur, Amal R Chowdhury. Physiological and subjective assessment of food grain handling workers in West Godavari district, India. Kolkata: Journal of Industrial Health, ROHC, ICMR, 2007;45:165-169.

10. Ayoub MM, Mital A. Manual material handling. London: Taylor \& Francis, 1989;1085-1123.

11. Mital A, Nicholson AS, Ayoub MM. A guide to manual materials handling. London: Taylor \& Francis, 1997.

12. Ghosh SN, Nag PK. Muscular strains in different modes of load-handling. Ahmadabad: Elsevier Ltd. 1986;1:6470.

13. Christensen H, Pedersen MB, Sjøgaard G. A national cross-sectional study in the Danish wood and furniture industry on working postures and manual material handling. Ergonomics 1995;38:793-805.

14. Chatterjee BB, Samanta A. Energy expenditure in manual load carriage. Industrial Health 1981;19:145154.

15. Sen RN, Nag PK. Work organization of heavy load handling in India. Journal of Human Ergology 1975;4:103-13.

16. Astrand PO, Rodahl K. Textbook of work physiology. Taylor \& Francis, London. 1989;612.042 RODK.

17. Bhat MR, Rangaswamy C. A comparative study of lung functions in rice mill and saw mill workers. Indian Journal of Physiology \& Pharmacology 1991;35:27-30. 